the lion runs to his prey with his nose to the ground, and the action of the bloodhound is valuable on account of his fine scent. It seems with mind as mere knower and nonmanipulator of action these performances could not be put through.

144 Well Street, Hackney, May 26.

A. Bowman.

\section{Musical Sands.}

MAY I record the discovery of musical sands at places along the shore between Ramsgate and Kingsgate. The sand occurs in small patches close to the chalk cliffs, the largest patch being found at Joss Gap. In composition the sand is very similar to that of Studland Bay, but the individual grains are more polished, and the proportion of denser minerals far higher. Of course, the sand can only be experimented upon when it has been uncovered by the sea for a sufficient length of time to enable it to become dry, and it gives remarkable results when tested in the ordinary way-especially when placed in a china vessel and struck with a wooden plunger.

June 8. Cecil Carus-Wilson.

\section{THE STUDY OF BACTERIAL TOXINS.}

$7 \mathrm{HE}$ study of the toxins produced by bacteria is one of the most important branches of bacteriological research. The solution of some of the main problems of immunity and disease depends upon the knowledge that can be gained with reterence to the nature of the bacterial toxins and their mode of action upon the animal body.

The methods introduced by Pasteur, Koch, and other observers have rendered it possible to detect and to isolate the specific agents in a number of infective processes. The number of infective diseases that have been definitely associated with the action of bacteria is considerable, e.g. tuberculosis, cholera, diphtheria, typhoid fever, \&c.

It was natural that the earliest attempts to prevent the invasion of the animal body by these microparasites should be based more or less on the principles of Jennerian vaccination. An attenuated virus, for example, was taken and used directly as a vaccine in order to produce, if possible, an active immunity to the disease in question. This system of protective inoculation was tested in a number of diseases, and notably in infective diseases of the lower animals. The anthrax vaccine employed for the protection of cattle and sheep is a typical example of such immunising methods, whilst in recent years analogous methods of protective inoculation have been extensively used in certain diseases of man.

The study of the microparasites associated with diphtheria and tetanus showed that organisms of this type possessed not merely infective but likewise marked toxic properties. It was further established that these toxic properties were the determining factors in the production of the graver symptoms in cases of diphtheria and tetanus. It therefore became apparent that in diseases of this order, the point of cardinal importance was to combat, if possible, the toxins produced in their course. The laboratory experiments made with the diphtheria and tetanus organisms demonstrated that the poisons were soluble products of the bacterial cells in question, and were excreted into the nutrient fluids in which they had been cultivated. These toxins were proved to be of a specific nature, as they reproduced the essential general symptoms of the diseases.

Diphtheria and tetanus are therefore intoxications of the body, due to the action of specific soluble poisons produced by the parasites at the seat of infection. The toxins, on being introduced into suitable animals in carefully regulated doses, produced an active immunisation of the animals characterised by the formation in their blood of anti-bodies as regards the toxins in question-in other words, antitoxins resulted. The antitoxic serum, when added to the toxin in vitro, robbed the toxin of its poisonous properties, and, probably in virtue of some chemical combination between toxin and antitoxin, a neutral mixture resulted. The serum containing these specific anti-bodies, on introduction into other animals, conferred on them a passive immunity. They were protected against the action of the toxin in question, and, most important of all, the serum was efticacious in the case of an already existing intoxication-it possessed curative as well as protective properties. If a large animal, such as a horse, was actively immunised by injection of the soluble toxins, considerable quantities of these antitoxic substances were formed and accumulated in its blood and bloodserum. In this way the serum of an animal highly charged with antitoxins became a valuable and innocuous vehicle for the introduction of these preventive and curative substances into the human system. The natural defensive forces of the body were thereby reinforced, and in the right direction. This method of serum therapeutics has had brilliant results in the case of diphtheria, and has been demonstrated to be a feasible therapeutic method in the case of tetanus. These maladies belong to the group of intoxicative diseases. There remained, on the other hand, a large number of diseases in which a general multiplication of the microorganisms in their host appeared to be the salient feature. It has been usual to call these, in contradistinction to the former, infective diseases. The successful results in the case of diphtheria led to the extensive study on similar lines of infective organisms generally. A systematic search was made for soluble bacterial poisons, as their detection would be likely to lead to valuable additions to antitoxic serum therapeutics.

The researches in this direction met with unexpected difficulties and disappointments. The results obtained in the case of diphtheria and tetanus were not found to be of general application. Each organism had therefore to be taken on its own merits, and individually studied. It speedily became apparent that, as regards a considerable number of infective agents, the conditions were not the same. On cultivation in fluid media no distinct evidence of the production of soluble poisons could be obtained, or, if present, they were so in an inappreciable amount. The attempts, therefore, to produce antitoxins by the injection of such culture fluids into animals did not promise to be of much practical value. This, as a matter of fact, has proved to be the case; the various serums prepared were found to possess little or no curative value. Many infective organisms did not apparently produce their injurious effects through the agency of soluble toxins, and consequently curative methods based on the assumption resulted in failure. Research was thrown back once more upon the living infective agents, and the possibilities there might be of protecting the body directly against their invasions, or, in other words, of producing not a poison but a bacterial immunity. Bactericidal substances were found to be present in the blood of individuals who had passed through an attack of certain infective diseases, and the bactericidal action was specific as regards the infective agent in each case. For example, the blood of a patient recovering from typhoid fever is bactericidal to the typhoid organism. In the absence of soluble immunising products, there was a strong presumption that these substances were to be sought for within the bodies of the bacteria. The bacteria in that case, if injected directly into the system, would tend to produce an active immunisation of the body, and would reinforce the bactericidal properties of the tissues in specific directions. The method most generally favoured for this purpose was the in-

NO. 1755 , vOL 68] 